\title{
Effects of delayed-release dimethyl fumarate on MRI measures in the phase 3 CONFIRM study
}

\section{OPEN}

David H. Miller, FMedSci

Robert J. Fox, MD

J. Theodore Phillips, MD, $\mathrm{PhD}$

Michael Hutchinson, FRCP

Eva Havrdova, MD

Mariko Kita, MD

Claudia A.M. Wheeler-

Kingshott, PhD

Daniel J. Tozer, PhD

David G. MacManus, MSc

Tarek A. Yousry, Dr Med Habil

Mary Goodsell, MSc Minhua Yang, MS

Ray Zhang, PhD

Vissia Viglietta, MD

Katherine T. Dawson, MD

For the CONFIRM study investigators

Correspondence to

Dr. Miller:

david.h.miller@ucl.ac.uk

Supplemental data at Neurology.org

\section{ABSTRACT}

Objective: To evaluate the effects of oral delayed-release dimethyl fumarate (DMF; also known as gastro-resistant DMF) on MRI lesion activity and load, atrophy, and magnetization transfer ratio (MTR) measures from the Comparator and an Oral Fumarate in Relapsing-Remitting Multiple Sclerosis (CONFIRM) study.

Methods: CONFIRM was a 2-year, placebo-controlled study of the efficacy and safety of DMF $240 \mathrm{mg}$ twice (BID) or 3 times daily (TID) in 1,417 patients with relapsing-remitting multiple sclerosis (RRMS); subcutaneous glatiramer acetate $20 \mathrm{mg}$ once daily was included as an active reference comparator. The number and volume of T2-hyperintense, T1-hypointense, and gadolinium-enhancing (Gd+) lesions, as well as whole brain volume and MTR, were assessed in 681 patients (MRI cohort).

Results: DMF BID and TID produced significant and consistent reductions vs placebo in the number of new or enlarging T2-hyperintense lesions and new nonenhancing T1-hypointense lesions after 1 and 2 years of treatment and in the number of $\mathrm{Gd}+$ lesions at week 24, year 1, and year 2. Lesion volumes were also significantly reduced. Reductions in brain atrophy and MTR changes with DMF relative to placebo did not reach statistical significance.

Conclusions: The robust effects on MRI active lesion counts and total lesion volume in patients with RRMS demonstrate the ability of DMF to exert beneficial effects on inflammatory lesion activity in multiple sclerosis, and support DMF therapy as a valuable new treatment option in RRMS.

Classification of evidence: This study provides Class I evidence of reduction in brain lesion number and volume, as assessed by MRI, over 2 years of delayed-release DMF treatment. Neurology ${ }^{\circledR}$ 2015;84:1145-1152

\section{GLOSSARY}

ANCOVA = analysis of covariance $\mathbf{B I D}=$ twice daily; $\mathbf{C I}=$ confidence interval; CONFIRM = Comparator and an Oral Fumarate in Relapsing-Remitting Multiple Sclerosis; DEFINE = Determination of the Efficacy and Safety of Oral Fumarate in RelapsingRemitting Multiple Sclerosis; DMF = delayed-release dimethyl fumarate (also known as gastro-resistant dimethyl fumarate); EDSS = Expanded Disability Status Scale; GA = glatiramer acetate; Gd+ = gadolinium-enhancing; ITT = intent-to-treat; $\mathbf{M S}=$ multiple sclerosis; $\mathbf{M T R}$ = magnetization transfer ratio; Nrf2 = nuclear factor (erythroid-derived 2)-like 2; PBVC = percentage brain volume change; RRMS = relapsing-remitting multiple sclerosis; SIENA = structural image evaluation using normalization of atrophy; SIENAX = structural image evaluation using normalization of atrophy cross-sectional; TID $=3$ times daily.

Multiple sclerosis (MS) is a chronic disease of the CNS, characterized by inflammatory demyelination and axonal degeneration, producing focal lesions of white and gray matter. Much of the damage in MS is thought to be caused by inflammation and associated oxidative stress; treatments that improve cellular resistance to inflammatory insults may broaden available options in MS therapy.

Oral delayed-release dimethyl fumarate (DMF; also known as gastro-resistant DMF) has demonstrated anti-inflammatory and cytoprotective effects mediated via both the nuclear factor (erythroid-derived 2)-like 2 (Nrf2) pathway and Nrf2-independent pathways in preclinical

From the Departments of Neuroinflammation (D.H.M., C.A.M.W.-K., D.J.T., D.G.M.) and Brain Repair and Rehabilitation (T.A.Y.), NMR Research Unit, Queen Square Multiple Sclerosis Centre; University College London Institute of Neurology (D.H.M., C.A.M.W.-K., D.J.T., D.G.M., T.A.Y.), UK; Mellen Center for Multiple Sclerosis Treatment and Research (R.J.F.), Cleveland Clinic, OH; Multiple Sclerosis Program (J.T.P.), Baylor Institute for Immunology Research, Dallas, TX; St. Vincent's University Hospital (M.H.), Elm Park, Donnybrook, Dublin, Ireland; Department of Neurology (E.H.), First Faculty of Medicine, Charles University, Prague, Czech Republic; Virginia Mason Medical Center (M.K.), Seattle, WA; CircleScience (M.G.), Tytherington, UK; and Biogen Idec Incorporated (M.Y., R.Z., V.V., K.T.D.), Weston, MA.

Coinvestigators are listed on the Neurology ${ }^{\circledR}$ Web site at Neurology.org.

Go to Neurology.org for full disclosures. Funding information and disclosures deemed relevant by the authors, if any, are provided at the end of the article. The Article Processing Charge was paid by Biogen Idec.

This is an open access article distributed under the terms of the Creative Commons Attribution-Noncommercial No Derivative 3.0 License, which permits downloading and sharing the work provided it is properly cited. The work cannot be changed in any way or used commercially. 
studies. ${ }^{1-4}$ Two randomized, double-blind, phase 3 studies, Determination of the Efficacy and Safety of Oral Fumarate in Relapsing-Remitting Multiple Sclerosis (DEFINE) and Comparator and an Oral Fumarate in Relapsing-Remitting Multiple Sclerosis (CONFIRM), were conducted among patients with relapsing-remitting MS (RRMS). ${ }^{5,6}$ In both studies, DMF treatment produced significant clinical and neuroradiologic benefits over 2 years, including reductions in relapses, new lesion counts, and lesion volumes assessed by MRI, with an acceptable safety profile.

DMF is approved in the United States for the treatment of relapsing forms of MS.7 Here, we report the effects of DMF on MRI brain lesions observed in CONFIRM. Tertiary analyses were also conducted to assess changes in brain volume (atrophy) and in magnetization transfer ratio (MTR), a quantitative MRI technique used to detect changes in intrinsic tissue structure, including myelin content, in the CNS. ${ }^{8-10}$

METHODS Standard protocol approvals, registrations, and patient consents. The CONFIRM study (ClinicalTrials.gov identifier NCT00451451) was approved by central and local ethics committees and performed in accordance with The International Conference on Harmonisation Guidelines on Good Clinical Practice $^{11}$ and the ethical principles outlined in the Declaration of Helsinki. ${ }^{12}$ Written informed consent was obtained from all patients before evaluations were performed to determine eligibility.

Study design. CONFIRM was a 2-year, phase 3, randomized, international, multicenter, parallel-group, placebo-controlled study, with active reference comparator, that evaluated the safety and efficacy of DMF in patients with RRMS, as reported previously. ${ }^{6}$ Patients from 200 sites in 28 countries were randomized 1:1:1:1 to receive PO placebo, PO DMF $240 \mathrm{mg}$ twice daily (BID), PO DMF $240 \mathrm{mg} 3$ times daily (TID), or glatiramer acetate (GA) $20 \mathrm{mg}$ once daily by subcutaneous injection for 96 weeks. DMF and placebo treatments were double-blind, while GA treatment was rater-blind.

MRI secondary and tertiary outcomes of the study were assessed in a subset of patients at centers with appropriate imaging facilities. These included the number of new or enlarging T2-hyperintense, new nonenhancing T1-hypointense, and gadolinium-enhancing $(\mathrm{Gd}+)$ lesions; volume of T2-hyperintense, nonenhancing T1-hypointense, and $\mathrm{Gd}+$ lesions; percentage brain volume change (PBVC); and percentage change in whole brain MTR.

Patients. As reported previously, ${ }^{6}$ patients aged $18-55$ years with a confirmed diagnosis of RRMS according to McDonald criteria $2005^{13}$ and an Expanded Disability Status Scale (EDSS) score of $0-5.0$ were enrolled in the MRI portion of the trial at screening, prior to randomization (figure 1). Additional eligibility criteria are included in e-Methods on the Neurology ${ }^{\circledR}$ Web site at Neurology.org.

MRI assessments. MRI scans were obtained at baseline and at weeks 24, 48, and 96 in patients from a subset of sites with full MRI capabilities. Approximately $95 \%$ of patients at these sites chose to participate. Original MRI scans from each site were evaluated in a blinded manner by qualified personnel at a central reading facility (University College London Institute of Neurology, UK).

Lesion volumes (T2-weighted and nonenhancing T1-weighted) were assessed at baseline and weeks 48 and 96, and numbers of new or enlarging T2-weighted lesions and new nonenhancing T1-weighted lesions were assessed at weeks 48 and 96. Gd+ lesion count and volume were assessed at baseline and weeks 24,48 , and 96 . Lesion assessment methodology is provided in e-Methods.

Normalized brain volume was assessed at baseline and week 24 using the structural image evaluation using normalization of atrophy (SIENA) cross-sectional (SIENAX) method, and PBVC was assessed at each post-baseline MRI visit relative to earlier measurements by the SIENA method. ${ }^{14} \mathrm{~A}$ more stringent post hoc quality assessment and analysis of PBVC is also included (methodology described in e-Methods). MTR analysis was conducted using a purposefully developed pipeline (methodology described in e-Methods). Median whole brain MTR at baseline, week 48, and week 96 was reported.

Statistical analyses. The intent-to-treat (ITT) population comprised all randomized patients who received at least one dose of study treatment. The MRI cohort comprised ITT patients who consented to participate in the MRI portion of the study and had any MRI data.

A negative binomial regression model was used to analyze the total number of new or enlarging T2-hyperintense lesions and the number of new T1-hypointense lesions at 2 years (secondary endpoints) and 1 year (tertiary endpoints). The model was adjusted for region (defined by type of health care system, access to health care, and geography) and baseline lesion volume (T1-hypointense or T2-hyperintense). The number of $\mathrm{Gd}+$ lesions at 1 and 2 years (tertiary endpoints) were analyzed using an ordinal logistic regression model, adjusted for region and baseline $\mathrm{Gd}+$ lesion number.

Analysis of covariance (ANCOVA) on ranked data was used to assess the effects of treatment on volume of T1-hypointense, T2-hyperintense, and $\mathrm{Gd}+$ lesions at 1 and 2 years (tertiary endpoints). The model included treatment group and adjustments for region and baseline lesion volume (T1-hypointense, T2-hyperintense, or $\mathrm{Gd}+$ ).

ANCOVA of ranked data was used to assess the effects of treatment on PBVC at 2 years, relative to baseline and relative to week 24. The model included treatment group and adjustments for region and brain volume at reference visit (baseline or week 24).

ANCOVA was also used to assess the effects of treatment on the percentage change from baseline of whole brain MTR at 1 and 2 years. The model included treatment group and adjustments for region and baseline MTR value.

Linear relationships between MRI endpoints and clinical endpoints were calculated using Spearman rank correlation coefficients.

Classification of evidence. This study provides Class I evidence of reduction in brain lesion number and volume, as assessed by MRI, over 2 years of treatment with DMF $240 \mathrm{mg}$ BID or TID, compared with placebo, in patients with RRMS. DMF BID and TID reduced the mean number of new or enlarging T2-hyperintense lesions by $71 \%$ and $73 \%$, respectively, the mean number of new nonenhancing T1-hypointense lesions by $57 \%$ and $65 \%$, and $\mathrm{Gd}+$ lesions by $74 \%$ and $65 \%$ (reductions in the odds of having more lesions) over 2 years vs placebo (all $p<0.001)$. Lesion volumes were also significantly reduced.

RESULTS Patients. Of the 1,430 patients randomized, 1,417 were included in the ITT population, and 681 patients in the MRI cohort (figure 1). Baseline 


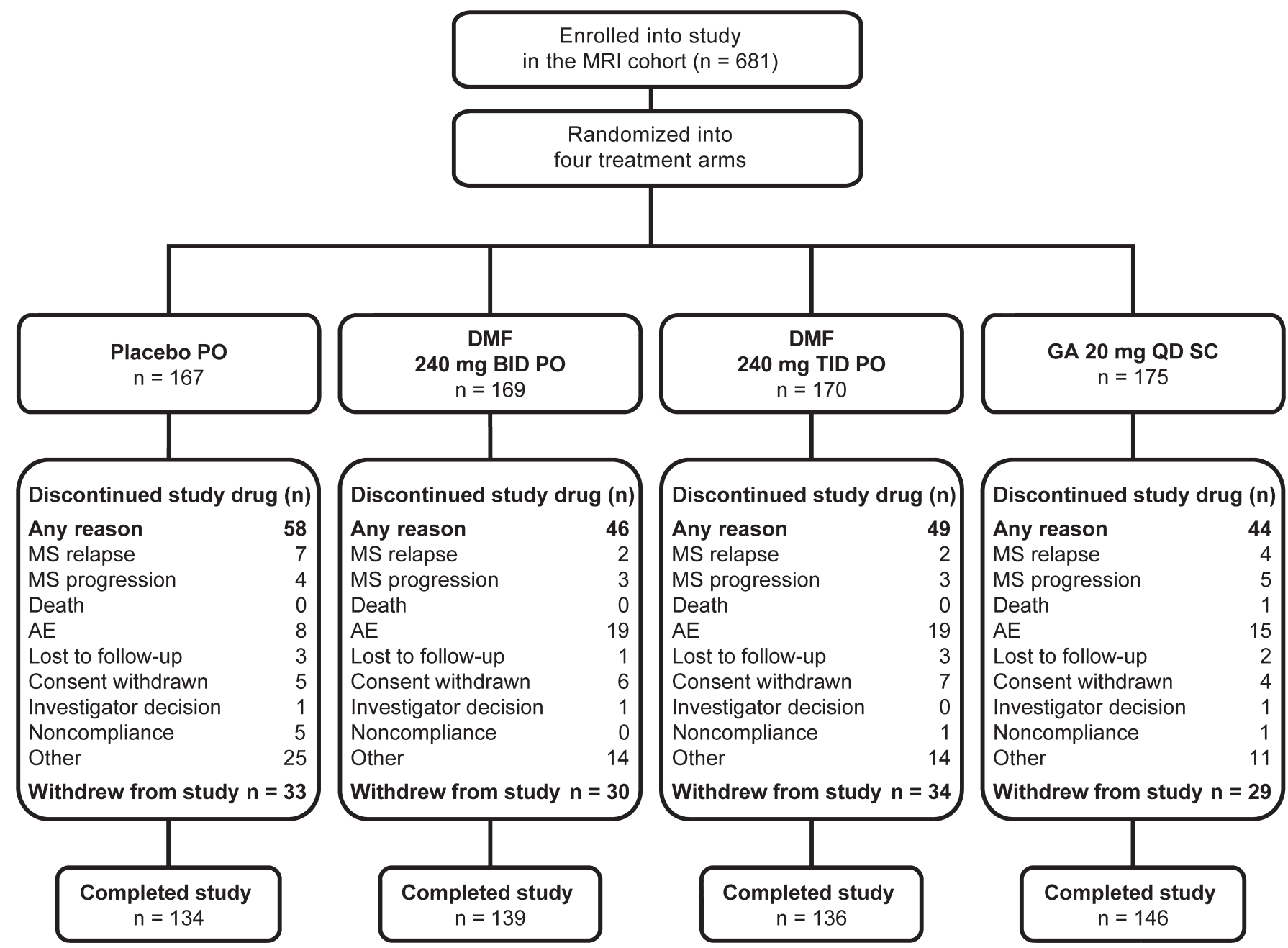

Final intent-to-treat population of patients who were enrolled in the MRI cohort and then randomized and received at least 1 dose of study treatment was $n=$ 681. $\mathrm{AE}=$ adverse event; $\mathrm{DMF}=$ delayed-release dimethyl fumarate (also known as gastro-resistant DMF); $\mathrm{GA}=$ glatiramer acetate; $\mathrm{MS}=$ multiple sclerosis; $\mathrm{QD}=$ once daily; $\mathrm{SC}=$ subcutaneous.

demographic and disease characteristics of the MRI cohort were comparable among treatment groups (table 1) and with the non-MRI cohort (tables e-1 and e-2).

Lesion number. Compared with placebo, DMF BID and TID reduced the mean number of new or enlarging T2-hyperintense lesions that developed over 2 years by $71 \%$ and $73 \%$, respectively (both $p<0.0001$ ) (figure $2 \mathrm{~A}$ and table e-3). This robust effect was evident at 1 year and was maintained at 2 years. DMF reduced the number of new or enlarging T2-hyperintense lesions by $67 \%$ (BID) and 70\% (TID) during the first year, and by $76 \%$ (both groups) during the second year (all $p<0.0001$ ). In the GA group, the relative reduction in mean T2-hyperintense lesion number vs placebo was $54 \%$ over 2 years: $52 \%$ in the first year and $57 \%$ in the second year (all $p<0.0001)$.

Compared with placebo, DMF reduced the mean number of new nonenhancing T1-hypointense lesions that developed over 2 years by 57\% (BID) and $65 \%$ (TID) ( $p<0.0001$ for both comparisons), with respective relative reductions of $41 \%(p=0.0030)$ and $60 \%(p<0.0001)$ in the first year, and $70 \%$ and $71 \%$ (both $p<0.0001$ ) in the second year (figure 2B and table e-4). Relative to placebo, GA reduced the mean new nonenhancing T1-hypointense lesion number by $41 \%$ ( $p=0.0021$ ) over the 2 years: $30 \%$ in the first year and $55 \%$ in the second year $(p=0.0402$ and 0.0002 , respectively).

DMF also reduced Gd+ lesions at 6 months, with relative reductions over placebo of $81 \%$ (BID) and $69 \%$ (TID) (reductions in the odds of having more lesions; $p<0.0001$ for both comparisons); the relative reduction with GA at this time point was $42 \%$ $(p=0.0201)$ (figure 2C and table e-5). Relative odds reductions over placebo in $\mathrm{Gd}+$ lesions were $87 \%$ (BID), 77\% (TID), and 63\% (GA) (all $p<0.0001$ ) at 1 year and $74 \%$ (BID, $p<0.0001$ ), 65\% (TID, $p=0.0001)$, and $61 \%(\mathrm{GA}, p=0.0003)$ at 2 years. 
Table 1 Key baseline demographics and disease characteristics for the MRI cohort

\begin{tabular}{|c|c|c|c|c|}
\hline Characteristics & Placebo $(n=167)$ & DMF BID $(n=169)$ & DMF TID $(n=170)$ & $\mathrm{GA}(\mathrm{n}=175)$ \\
\hline Age, $y$, mean (SD) & $36.6(9.1)$ & 38.5 (8.9) & $38.2(9.7)$ & $36.8(8.8)$ \\
\hline Female, $n(\%)$ & $116(69)$ & $118(70)$ & $121(71)$ & $123(70)$ \\
\hline 1 criterion & $142(85)$ & $139(82)$ & $147(86)$ & $150(86)$ \\
\hline 2-4 criteria & $25(15)$ & $30(18)$ & $23(14)$ & 25 (14) \\
\hline Relapses in previous year, mean (SD) & $1.3(0.6)$ & $1.3(0.7)$ & $1.3(0.7)$ & $1.3(0.7)$ \\
\hline EDSS score at baseline, mean (SD) ${ }^{b}$ & $2.5(1.1)$ & $2.5(1.1)$ & 2.5 (1.2) & 2.5 (1.3) \\
\hline T2 lesion volume, mean (SD) $\mathrm{mm}^{3}$ & $14,595(13,267)$ & $13,876(13,348)$ & $12,827(13,385)$ & $13,789(13,562)$ \\
\hline Median & 10,822 & 9,701 & 7,767 & 9,435 \\
\hline Patients with Gd+ lesions, $n$ (\%) & $79(47)$ & $82(49)$ & $70(41)$ & $78(45)$ \\
\hline Normalized whole brain volume, mean (SD) $\mathrm{cm}^{3}$ & $1,496(93)$ & $1,498(98)$ & 1,487 (103) & $1,484(138)$ \\
\hline
\end{tabular}

Abbreviations: DMF = delayed-release dimethyl fumarate (also known as gastro-resistant DMF); EDSS = Expanded Disability Status Scale; GA = glatiramer acetate; $\mathrm{Gd}+=$ gadolinium-enhancing; $\mathrm{MS}=$ multiple sclerosis.

${ }^{a}$ Interferon $\beta-1 \mathrm{a}(20 \%)$, interferon $\beta-1 \mathrm{~b}(11 \%)$, natalizumab (1\%), and GA $(<1 \%)$, all balanced across groups; one patient was randomized to GA who had previously been exposed to GA. Patients may have received more than one prior MS medication. Patients may also have received other nonapproved therapies for MS (the proportion of patients in the MRI cohort receiving any MS medication prior to study was $28 \%-29 \%$ across treatment groups).

${ }^{\mathrm{b}}$ Score on the EDSS scale, which ranges from 0 to 10, with higher scores indicating greater degree of disability.

${ }^{\mathrm{c}}$ From T1-weighted scans.

The robustness of these findings was confirmed by sensitivity analyses based on all observed data, and on observed data prior to starting alternative MS medication (figure e-1). These sensitivity analyses indicated that neither the data imputation method used in the primary analysis nor the exclusion of data after patients switched to alternative MS medication affected the results.

Although this study was not designed to assess superiority or noninferiority of DMF over GA, the reductions in lesion numbers over 2 years relative to placebo were numerically greater in both DMF dose groups than in the GA group. Direct comparisons (post hoc) of the relative effect of BID and TID vs GA produced rate ratios $(95 \%$ confidence intervals $[\mathrm{CI}])$ of $0.64(0.46,0.88)$ and $0.59(0.43,0.82)$ for new/enlarging T2-hyperintense lesions (nominal $p$ values for the comparison: $p=0.0068$ and $p=0.0017$ ), and 0.74 $(0.52,1.04)$ and $0.59(0.41,0.84)$ for new nonenhancing T1-hypointense lesions (nominal $p=0.0846$ and $p=0.0033)$, respectively. Odds ratios $(95 \% \mathrm{CI})$ for $\mathrm{Gd}+$ lesions were $0.71(0.40,1.25)$ for BID and 0.87 $(0.50,1.52)$ TID vs GA (not significant).

Lesion volume. A reduction in T2-hyperintense lesion volume was seen within the first year of DMF treatment, and was maintained throughout the study. Lesion volume increased in the placebo group, with mean \pm SD change from baseline to 2 years of $744.7 \pm 3,662.4 \mathrm{~mm}^{3}$, representing a median $15 \%$ increase from baseline, vs a reduction in T2hyperintense lesion volume by $1,035.8 \pm 2,657.2$, $800.5 \pm 3,933.3$, and $946.0 \pm 3,766.6 \mathrm{~mm}^{3}$ (median percentage change $-7 \%,-2 \%$, and $-6 \%$ ) in the BID, TID, and GA groups, respectively $(p<0.0001$ for all comparisons vs placebo) (figure 2D and table e-3).

Increases in nonenhancing T1-hypointense lesion volume at 2 years were attenuated with DMF treatment relative to placebo, with mean \pm SD changes from baseline of $198.1 \pm 1,380.0(\mathrm{BID})$ and $190.7 \pm 1,204.2$ (TID), vs $342.4 \pm 878.5 \mathrm{~mm}^{3}$ with placebo (median percentage change $11 \%$ and $9 \%$ vs $20 \% ; p=0.0005$ and $p=0.0015$ vs placebo), respectively (figure $2 \mathrm{E}$ and table e-4). Treatment with GA also attenuated the increase in T1-hypointense lesion volume at 2 years relative to placebo, with mean $\pm S D$ change from baseline of $214.7 \pm 1,389.0 \mathrm{~mm}^{3}$ (median percentage change $9 \%, p=0.0013$ vs placebo).

Compared with placebo, DMF reduced Gd+ lesion volumes, with mean \pm SD values at 2 years of $35.9 \pm$ 128.5 (BID) and $42.6 \pm 149.9 \mathrm{~mm}^{3}$ (TID), compared with $141.8 \pm 339.1 \mathrm{~mm}^{3}$ for placebo (post hoc analysis; both $p<0.0001$ vs placebo) (figure $2 \mathrm{~F}$ and table e-5). This treatment effect was apparent within 6 months. The mean $\pm S D$ reduction from baseline to 2 years in $\mathrm{Gd}+$ lesion volume was $251.8 \pm 595.6$ (BID) and 
A. New/enlarging $\mathrm{T} 2$ lesions ${ }^{\mathrm{a}}$ (lesion number)

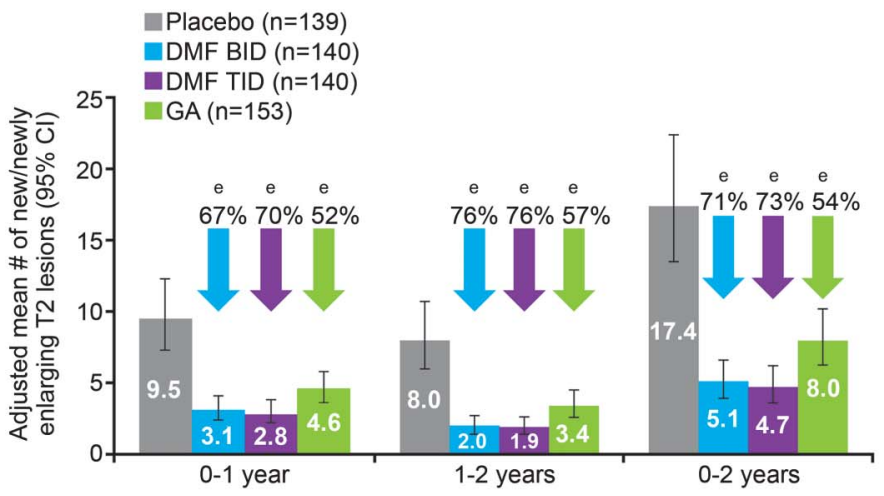

C. Gd+ lesions ${ }^{b}$ (lesion number)

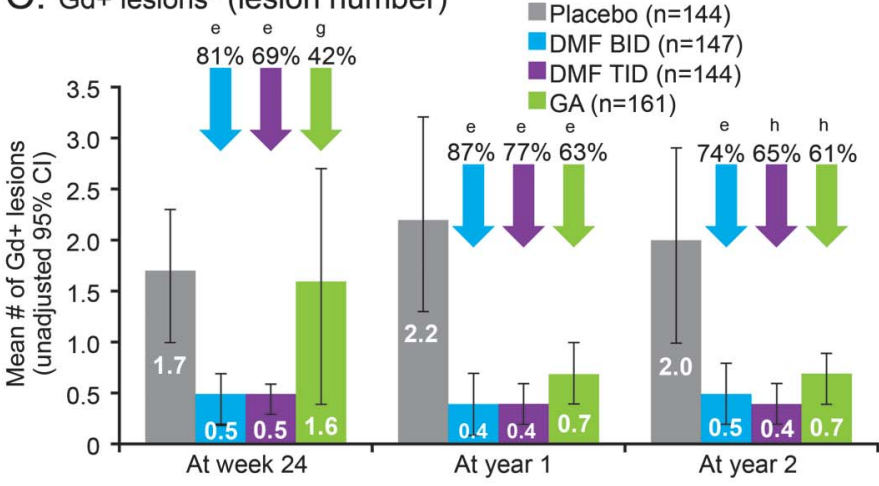

E. T1-hypointense lesions ${ }^{\mathrm{c}}$ (lesion volume)

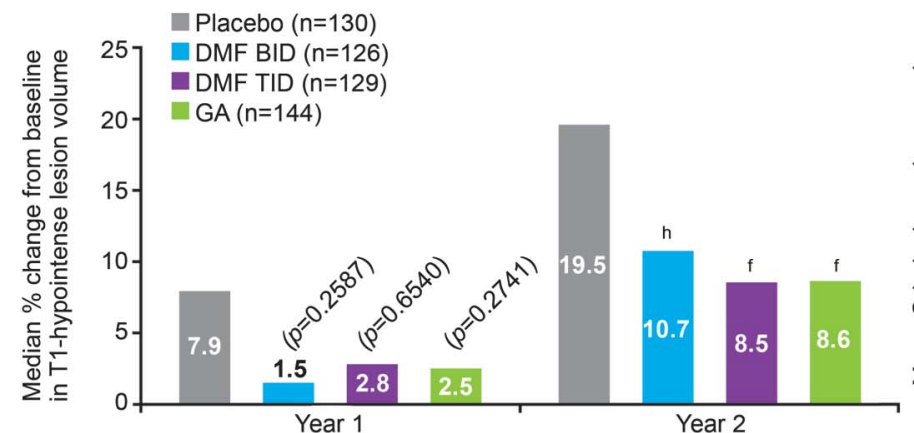

B. New nonenhancing T1-hypointense lesions ${ }^{\mathrm{a}}$ (lesion number)

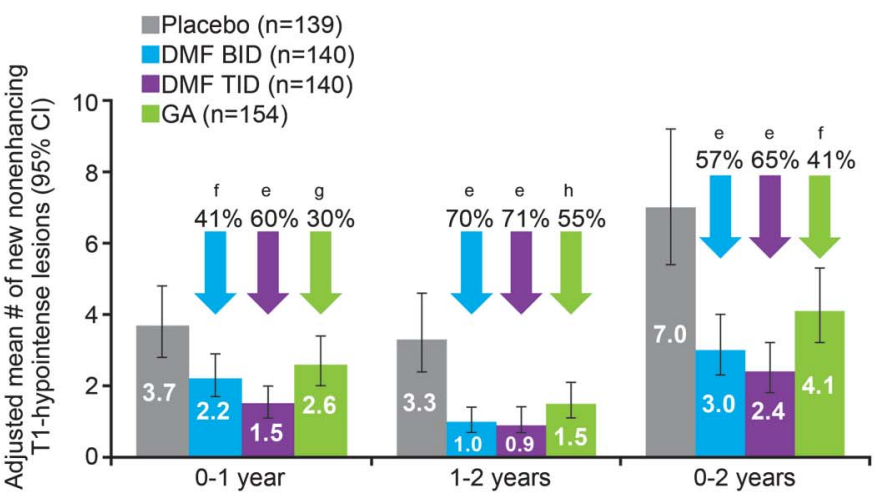

D. T2 lesions ${ }^{c}$ (lesion volume)

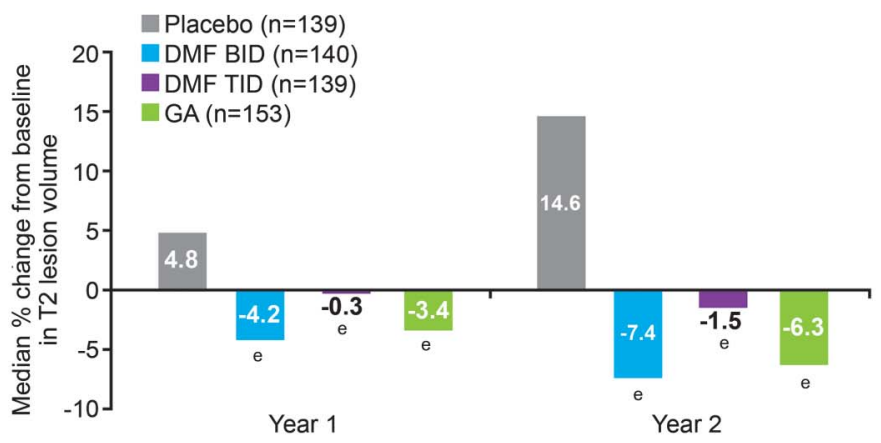

F. Gd+ lesions ${ }^{\mathrm{c}, \mathrm{d}}$ (lesion volume)

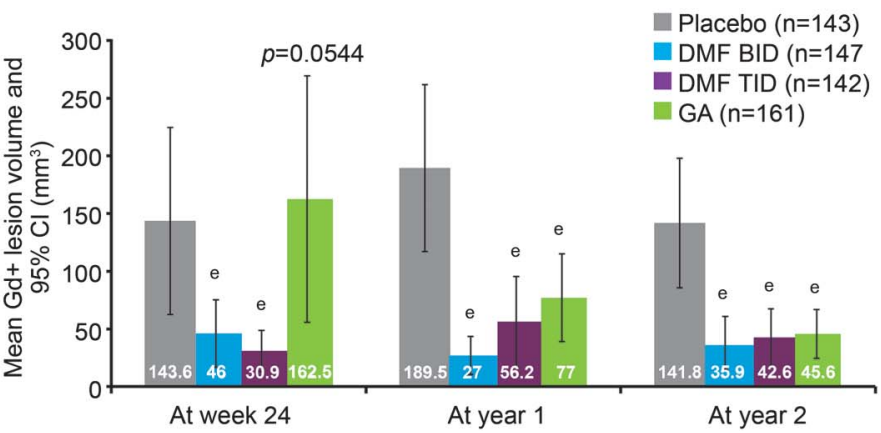

Patient numbers refer to those who provided data both at baseline and at each scheduled MRI analysis. Relative reductions (vs placebo) in the risk of having a greater number of gadolinium-enhancing $(\mathrm{Gd}+)$ lesions were based on the odds ratio from the prespecified analysis model of ordinal logistic regression (a conservative method, chosen to minimize undue influence of outlier $\mathrm{Gd}+$ lesion counts on the estimated treatment effect), for categories of patients with $0,1,2,3-4$, and $\geq 5$ lesions. Comparisons vs placebo were based on anegative binomial regression, adjusted for region and baseline lesion volume; bordinal regression, adjusted for region and baseline lesion number; and canalysis of covariance on ranked data, adjusted for region and baseline lesion volume. ${ }^{\mathrm{d} T h e}$ comparison vs placebo of mean $\mathrm{Gd}+$ lesion volume at postbaseline timepoints was a post hoc analysis (change from baseline was the prespecified analysis). ${ }^{\mathrm{e}} \mathrm{p}<0.0001 ;{ }^{\mathrm{f}} \mathrm{p}<0.01 ;{ }^{9} \mathrm{p}<0.05 ;{ }^{\mathrm{h}} \mathrm{p}<0.001$ for comparison vs placebo. $\mathrm{Cl}=$ confidence interval; $\mathrm{DMF}=$ delayed-release dimethyl fumarate (also known as gastro-resistant DMF); GA = glatiramer acetate.

$181.7 \pm 738.5 \mathrm{~mm}^{3}$ (TID), compared with $7.2 \pm$ $448.6 \mathrm{~mm}^{3}$ (placebo), and the median percentage change from baseline was $-100 \%$ (BID) and $-100 \%$ (TID) (both $p<0.0001$ vs placebo, $+14 \%)$ (table e-5). In patients treated with $\mathrm{GA}, \mathrm{Gd}+$ lesion volume was $45.6 \pm 135.8 \mathrm{~mm}^{3}$ at 2 years (post hoc analysis; $p<$ 0.0001 vs placebo) and was reduced from baseline to 2 years by $202.5 \pm 573.5 \mathrm{~mm}^{3}$ (median percentage change from baseline $-100 \%, p<0.0001$ vs placebo).

Brain atrophy and whole brain MTR. Median PBVC from baseline to 2 years was less than $1 \%$ in the placebo group as well as the active treatment groups (figure 3), indicating a relatively low average rate of 


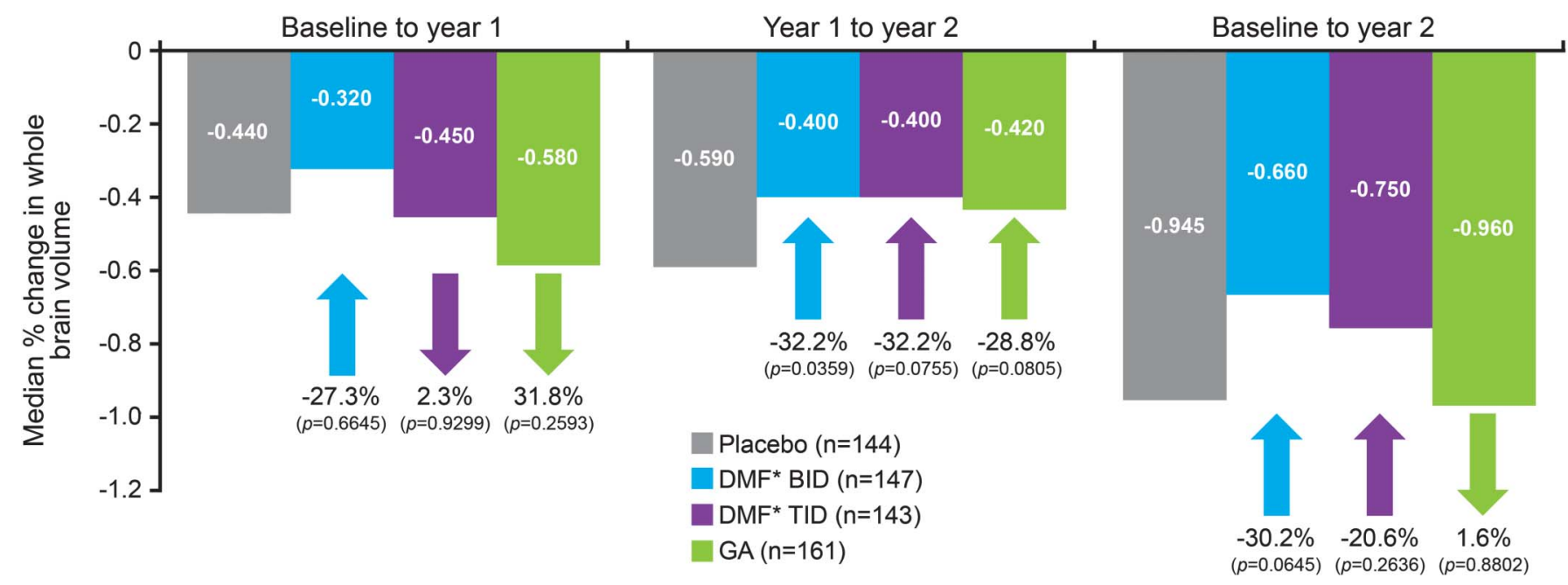

Measured using the structural image evaluation, using normalization, of atrophy method. *DMF = delayed-release DMF (also known as gastro-resistant $\mathrm{DMF}) ; \mathrm{GA}=$ glatiramer acetate.

atrophy during the study. Data from baseline to week 24 showed no evidence of pseudoatrophy in active treatment arms (table e-6). At 2 years, PBVC favored DMF, but not GA, relative to placebo, although none of the changes reached statistical significance: the median decrease in PBVC was 30\% (BID; $p=$ $0.0645)$ and $21 \%$ (TID; $p=0.2636$ ) relative to placebo, vs a median relative increase of $2 \%$ for GA vs placebo $(p=0.8802)$. Between years 1 and 2 , there was a $32 \%$ reduction in atrophy with DMF relative to placebo $(p=0.0359[\mathrm{BID}]$ and $p=0.0755[\mathrm{TID}])$, and $28.8 \%$ reduction in the GA group $(p=$ 0.0805), based on median PBVC values. Similar results were obtained in the more stringent post hoc quality assurance reanalysis of PBVC (table e-7). At 2 years, mean (median) percentage changes in MTR from baseline were -0.167 (0.000), -0.008 (0.000), and $+0.010(0.000)$ for DMF BID, TID, and GA groups, respectively, compared with -0.419 $(-0.323)$ for placebo (table e-8); none of the relative changes in MTR reached statistical significance compared with placebo.

Subgroup analysis. Compared with placebo, DMF (BID or TID) was associated with robust reductions in numbers of new/enlarging T2-hyperintense lesions and $\mathrm{Gd}+$ lesions across a range of prespecified patient subpopulations stratified by baseline characteristics (sex, age $<40$ vs $\geq 40$ years, $\leq 1$ vs $\geq 2$ relapses in the year prior to study, McDonald criteria, prior MS treatment status, EDSS score, T2 lesion volume, and Gd+ lesion status) (figure e-2).

Clinical-MRI correlations. In the overall cohort after 2 years, there were significant correlations of change in $\mathrm{T} 2$ and $\mathrm{T} 1$ lesion load and in new lesion counts with relapse rate, and no significant correlation of PBVC (tertiary endpoint) with change in EDSS (table e-9).

DISCUSSION MRI is an important tool for monitoring disease activity and is widely used in clinical trials of MS therapies. In this study, we have shown that DMF significantly reduced disease activity as measured by MRI active lesion number (an indicator of recent inflammation that correlates with relapse rates) $)^{15,16}$ and disease progression, as measured by total lesion volume (an indicator of overall disease burden), ${ }^{17}$ compared with placebo. These effects were evident at the first MRI assessment for T2-hyperintense lesions and Gd+ lesions (1 year and 6 months, respectively) and persisted over the 2-year evaluation period. Furthermore, these findings were accompanied by reductions in new nonenhancing T1-hypointense lesions relative to placebo, which may suggest an effect of DMF in reducing tissue damage since persistent T1-hypointense lesions are known to correlate with axonal loss. ${ }^{18}$

The MRI lesion outcomes observed in CONFIRM are consistent with the robust benefits reported in the phase 3 DEFINE study ${ }^{5}$ and the phase 2 clinical study with DMF. ${ }^{19-21}$ Although interpretation of comparisons between studies is limited by many considerations, including differences in study design, populations, endpoints, and standards of care at the time of study conduct, these MRI lesion outcomes for patients treated with DMF are generally comparable with those reported in other phase 3 studies of investigational and marketed oral MS therapies. ${ }^{5,22-25}$ The MRI findings observed with DMF also compare favorably with the MRI lesion outcomes seen in the GA arm of this trial, reinforcing the findings of indirect comparison of clinical outcomes of this study that have been reported elsewhere. ${ }^{6}$ 
The MRI outcomes in CONFIRM and other clinical studies are consistent with preclinical data, ${ }^{2,4,26}$ suggesting that anti-inflammatory properties may contribute to the efficacy of DMF in RRMS. This is illustrated by the significant reductions in new or enlarging T2-hyperintense, new T1-hypointense, and $\mathrm{Gd}+$ lesion counts, and total lesion volume. The MRI benefits of DMF are observed across patient subgroups differing in baseline disease activity and demographic characteristics (despite limited patient numbers), further supporting the potential value of this treatment across a broad spectrum of patients with RRMS.

MTR has not been explored previously in a large phase 3 study and, therefore, investigation of MTR in the present study and companion phase 3 study, DEFINE, represents a novel approach to obtain exploratory information and guide future study design. Brain atrophy data were also collected for tertiary analysis. Statistically significant treatment effects of DMF on MTR outcomes (both doses) and brain atrophy (BID only) were observed in DEFINE. ${ }^{27,28}$ However, MTR outcomes and brain atrophy results with DMF did not reach statistical significance in CONFIRM. The rate of atrophy in the placebo arm during the CONFIRM study was lower in comparison with the placebo arms of other phase 3 studies of oral MS therapies. ${ }^{22,24}$ In addition, there was no increase in brain volume loss with DMF during the first 24 weeks, indicating no significant pseudoatrophy effect due to a decrease in inflammatory tissue and edema.

Neither of the phase 3 studies was prospectively powered to detect a treatment effect on brain atrophy and MTR. Assessments of these parameters were performed in the MRI cohort that was about half the size of the whole trial population. The relatively small changes in MTR and atrophy measures in all study arms, including placebo, combined with the smaller sample size, may have reduced the sensitivity to detect a significant therapeutic effect over 2 years. A delayed onset of effect may also be relevant, as suggested by more evident reductions in PBVC in the DMF arms during the second year.

Previous trials of GA in clinically isolated syndromes $^{29}$ and RRMS $^{30}$ revealed $28 \%$ less brain atrophy and no difference in brain volume change after a mean follow-up of 3.8 years and 18 months, respectively. Although we did not observe less PBVC over 2 years in the GA-treated arm vs placebo, there was a trend for less atrophy in the second year.

Overall, the CONFIRM imaging data are consistent with DMF having robust anti-inflammatory effects. The positive imaging findings, when considered alongside clinical relapse and disability data, as well as the acceptable tolerability and safety profile of this agent, ${ }^{5,6}$ support the use of DMF as a valuable new treatment option in RRMS.

\section{AUTHOR CONTRIBUTIONS}

D.H.M. assisted in designing the study, supported centralized collection of the MRI data, overviewed analysis and interpretation of the study data, and cowrote the manuscript. R.J.F., J.T.P., E.H., and M.K. designed the study, collected and interpreted the data, and reviewed the manuscript. M.H. served on the medical advisory board, reviewed drafts, and was involved in data collection. C.A.M.W.-K., D.J.T., D.G.M., and T.A.Y. collected, analyzed, and interpreted the data and reviewed the manuscript. M.G. conducted literature searches, wrote an earlier draft of the manuscript, prepared figures, and edited the manuscript under the direction of the other authors. M.Y. was involved in the study design, analyzed the data, and reviewed the manuscript. R.Z. analyzed the data and reviewed the manuscript. V.V. interpreted the data and reviewed the manuscript. K.T.D. designed the study, interpreted the data, and cowrote the manuscript.

\section{STUDY FUNDING}

The CONFIRM study was funded by Biogen Idec Inc., Weston, MA. Medical writing and editorial support were provided by CircleScience (Tytherington, UK) and funded by Biogen Idec Inc. The NMR Research Unit at the Queen Square MS Centre is supported by the UK MS Society and UCLH-UCL Biomedical Research Centre.

\section{DISCLOSURE}

D. Miller has received honoraria through payments to his employer, UCL Institute of Neurology, for advisory committee and/or consultancy advice in multiple sclerosis studies from Bayer Schering Pharma, Biogen Idec, Novartis, Mitsubishi Pharma Europe, Merck, and GlaxoSmithKline; and research support through payments to his employer, UCL Institute of Neurology, from Apitope, Biogen Idec, GlaxoSmithKline, Novartis, and Schering AG. R. Fox reports receiving consulting fees from Allozyne, Avanir, Biogen Idec, Novartis, Questcor, and Teva; and grant and research support from Novartis. J. Phillips reports receiving consulting fees from Acorda, Biogen Idec, Genzyme, Novartis, and Teva; and research support from Biogen Idec and Roche. M. Hutchinson has received speaker's honoraria from Bayer Schering, Biogen Idec, and Novartis; editorial fees from the Multiple Sclerosis Journal; and research grants from the Health Research Board, Ireland, and Dystonia Ireland. E. Havrdova reports receiving consulting and lecture fees from Bayer, Biogen Idec, Genzyme, Novartis, Serono, and Teva; and research support from the Czech Ministry of Education (MSM 0021620849, PRVOUK-P26/LF1/4). M. Kita has received travel support and research grant funding from Biogen Idec and served on a speaker's bureau for Genzyme. C. Wheeler-Kingshott reports receiving consulting fees from Biogen Idec. D. Tozer has a portion of his salary paid by Biogen Idec and Novartis for work involving analysis of MRI data in MS trials. D. MacManus has received research grants (held by University College London) from Apitope, Biogen Idec, GlaxoSmithKline, Novartis, Richmond Pharma, and Schering AG for analysis of MRI data in MS trials. T. Yousry has received honoraria and travel expenses for advisory committee work from Bayer Schering, Biogen Idec, and Novartis; and research grants (held by University College London) from Biogen Idec, GlaxoSmithKline, Novartis, and Schering AG for analysis of data from MS trials. M. Goodsell was an employee of CircleScience at the time of writing, which has been contracted by Biogen Idec to provide medical writing services. M. Yang reports being an employee of and holding stock in Biogen Idec. R. Zhang reports being an employee of and holding stock in Biogen Idec. V. Viglietta reports being an employee of and holding stock in Biogen Idec. K. Dawson reports being an employee of and holding stock in Biogen Idec. Go to Neurology.org for full disclosures.

Received June 14, 2013. Accepted in final form November 21, 2014.

\section{REFERENCES}

1. Ghoreschi K, Bruck J, Kellerer C, et al. Fumarates improve psoriasis and multiple sclerosis by inducing type II dendritic cells. J Exp Med 2011;208:2291-2303.

2. Linker RA, Lee DH, Ryan $S$, et al. Fumaric acid esters exert neuroprotective effects in neuroinflammation via activation of the Nrf2 antioxidant pathway. Brain 2011; 134:678-692. 
3. Loewe R, Holnthoner W, Groger M, et al. Dimethylfumarate inhibits TNF-induced nuclear entry of NF-kappa B/p65 in human endothelial cells. J Immunol 2002;168: 4781-4787.

4. Scannevin RH, Chollate S, Jung MY, et al. Fumarates promote cytoprotection of central nervous system cells against oxidative stress via the Nrf2 pathway. J Pharmacol Exp Ther 2012;341:274-284.

5. Gold R, Kappos L, Arnold DL, et al. Placebo-controlled phase 3 study of oral BG-12 for relapsing multiple sclerosis. N Engl J Med 2012;367:1098-1107.

6. Fox RJ, Miller DH, Phillips JT, et al. Placebo-controlled phase 3 study of oral BG-12 or glatiramer in multiple sclerosis. N Engl J Med 2012;367:1087-1097.

7. US Food and Drug Administration. TECFIDERATM Prescribing Information. Available at: http://www. accessdata.fda.gov/drugsatfda_docs/label/2013/204063lbl. pdf. Accessed April 2, 2013.

8. Filippi M, Rocca MA, De Stefano N, et al. Magnetic resonance techniques in multiple sclerosis: the present and the future. Arch Neurol 2011;68:1514-1520.

9. Schmierer K, Scaravilli F, Altmann DR, et al. Magnetization transfer ratio and myelin in postmortem multiple sclerosis brain. Ann Neurol 2004;56:407-415.

10. Chen JT, Easley K, Schneider C, et al. Clinically feasible MTR is sensitive to cortical demyelination in MS. Neurology 2013;80:246-252.

11. International Conference on Harmonisation of technical requirements for registration of pharmaceuticals for human use. ICH harmonised tripartite guideline: Guideline for Good Clinical Practice. J Postgrad Med 2001;47:45-50.

12. World Medical Association. Declaration of Helsinki: Ethical Principles for Medical Research Involving Human Subjects. Available at: http://www.wma.net/en/30publications/ 10policies/b3/. Accessed November 22, 2010.

13. Polman $\mathrm{CH}$, Reingold SC, Edan G, et al. Diagnostic criteria for multiple sclerosis: 2005 revisions to the "McDonald criteria." Ann Neurol 2005;58:840-846.

14. Smith SM, Zhang Y, Jenkinson M, et al. Accurate, robust, and automated longitudinal and cross-sectional brain change analysis. Neuroimage 2002;17:479-489.

15. Kappos L, Moeri D, Radue EW, et al. Predictive value of gadolinium-enhanced magnetic resonance imaging for relapse rate and changes in disability or impairment in multiple sclerosis: a meta-analysis: Gadolinium MRI Meta-analysis Group. Lancet 1999;353:964-969.

16. Morgan CJ, Ranjan A, Aban IB, et al. The magnetic resonance imaging "rule of five": predicting the occurrence of relapse. Mult Scler 2013;19:1760-1764.
17. Brex PA, Ciccarelli O, O’Riordan JI, et al. A longitudinal study of abnormalities on MRI and disability from multiple sclerosis. N Engl J Med 2002;346:158-164.

18. Barkhof F. Assessing treatment effects on axonal loss: evidence from MRI monitored clinical trials. J Neurol 2004; 251(suppl 4):IV6-IV12.

19. Kappos L, Gold R, Miller DH, et al. Efficacy and safety of oral fumarate in patients with relapsing-remitting multiple sclerosis: a multicentre, randomised, double-blind, placebocontrolled phase IIb study. Lancet 2008;372:1463-1472.

20. Kappos L, Gold R, Miller DH, et al. Effect of BG-12 on contrast-enhancing lesions in patients with relapsingremitting multiple sclerosis: subgroup analyses from the phase 2b study. Mult Scler 2012;18:314-321.

21. Macmanus DG, Miller DH, Kappos L, et al. BG-12 reduces evolution of new enhancing lesions to T1-hypointense lesions in patients with multiple sclerosis. J Neurol 2011;258:449-456.

22. Comi G, Jeffery D, Kappos L, et al. Placebo-controlled trial of oral laquinimod for multiple sclerosis. $\mathrm{N}$ Engl J Med 2012;366:1000-1009.

23. Comi G, Cook SD, Giovannoni G, et al. MRI outcomes with cladribine tablets for multiple sclerosis in the CLARITY study. J Neurol 2013;260:1136-1146.

24. Radue EW, O'Connor P, Polman $\mathrm{CH}$, et al. Impact of fingolimod therapy on magnetic resonance imaging outcomes in patients with multiple sclerosis. Arch Neurol 2012;69:1259-1269.

25. Wolinsky JS, Narayana PA, Nelson F, et al. Magnetic resonance imaging outcomes from a phase III trial of teriflunomide. Mult Scler 2013;19:1310-1319.

26. Schilling S, Goelz S, Linker R, et al. Fumaric acid esters are effective in chronic experimental autoimmune encephalomyelitis and suppress macrophage infiltration. Clin Exp Immunol 2006;145:101-107.

27. Arnold D, Gold R, Kappos L, et al. Effects of BG-12 on magnetization transfer ratio in whole brain and normalappearing brain tissue: findings from the DEFINE study. Neurology 2012;78:S11.004.

28. Arnold D, Gold R, Kappos L, et al. Effect of BG-12 on brain atrophy and lesions volume: MRI results from the DEFINE study during first and second year of treatment. Neurology 2012;78:S11.003.

29. Comi G, Martinelli V, Rodegher M, et al. Effects of early treatment with glatiramer acetate in patients with clinically isolated syndrome. Mult Scler 2013;19:1074-1083.

30. Rovaris M, Comi G, Rocca MA, et al. Short-term brain volume change in relapsing-remitting multiple sclerosis: effect of glatiramer acetate and implications. Brain 2001; 124:1803-1812. 


\section{Neurology}

\section{Effects of delayed-release dimethyl fumarate on MRI measures in the phase 3 CONFIRM study}

David H. Miller, Robert J. Fox, J. Theodore Phillips, et al.

Neurology 2015;84;1145-1152 Published Online before print February 13, 2015

DOI 10.1212/WNL.0000000000001360

This information is current as of February 13, 2015

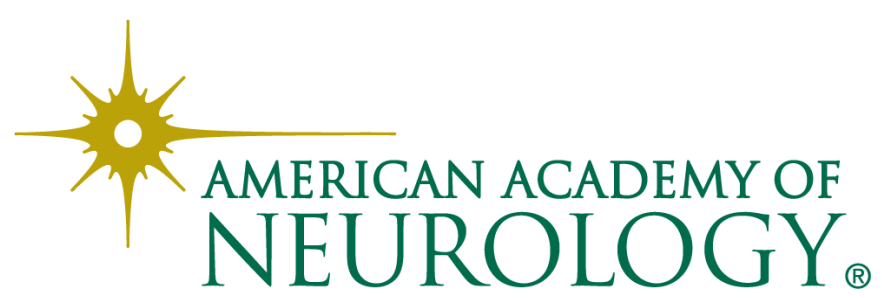




\section{Updated Information \& Services}

\section{Supplementary Material}

\section{References}

Subspecialty Collections

Permissions \& Licensing

\section{Reprints}

including high resolution figures, can be found at: http://n.neurology.org/content/84/11/1145.full

Supplementary material can be found at: http://n.neurology.org/content/suppl/2015/02/13/WNL.0000000000001 360.DC1

http://n.neurology.org/content/suppl/2015/02/13/WNL.0000000000001 360.DC2

This article cites 28 articles, 4 of which you can access for free at: http://n.neurology.org/content/84/11/1145.full\#ref-list-1

This article, along with others on similar topics, appears in the following collection(s):

\section{All Imaging}

http://n.neurology.org/cgi/collection/all_imaging

Class I

http://n.neurology.org/cgi/collection/class_1

Clinical trials Randomized controlled (CONSORT agreement)

http://n.neurology.org/cgi/collection/clinical_trials_randomized_control led_consort_agreement

MRI

http://n.neurology.org/cgi/collection/mri

Multiple sclerosis

http://n.neurology.org/cgi/collection/multiple_sclerosis

Information about reproducing this article in parts (figures,tables) or in its entirety can be found online at:

http://www.neurology.org/about/about_the_journal\#permissions

Information about ordering reprints can be found online:

http://n.neurology.org/subscribers/advertise

Neurology ${ }^{\circledR}$ is the official journal of the American Academy of Neurology. Published continuously since 1951, it is now a weekly with 48 issues per year. Copyright @ 2015 American Academy of Neurology. All rights reserved. Print ISSN: 0028-3878. Online ISSN: 1526-632X.

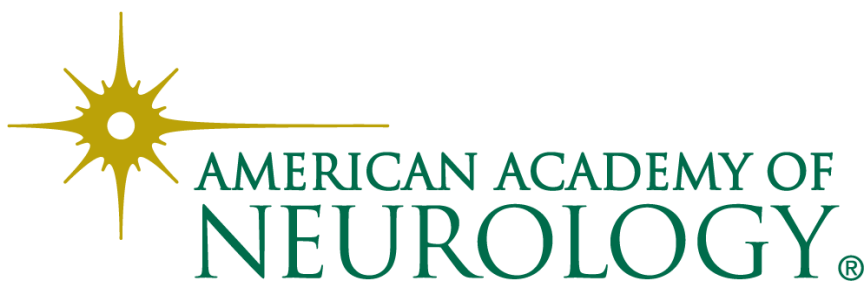

